\title{
Speech Outcomes of Korean Children with Bilateral Cleft Lip and Palate Following Primary Palatal Surgery
}

\author{
Seunghee Haa , Seungeun Jung ${ }^{\mathrm{b}}$, Kyung S. Koh', Tae Suk $\mathrm{Oh}^{\mathrm{c}}$ \\ ${ }^{a}$ Division of Speech Pathology and Audiology, Audiology and Speech Pathology Research Institute, Hallym University, Chuncheon, Korea \\ ${ }^{b}$ Department of Speech Pathology, Hallym University, Chuncheon, Korea \\ 'Department of Plastic Surgery, Asan Medical Center, Seoul, Korea
}

Correspondence: Seunghee $\mathrm{Ha}, \mathrm{PhD}$ Division of Speech Pathology and Audiology, Audiology and Speech Pathology Research Institute, Hallym University, 1 Hallimdaehak-gil, Chuncheon 24252, Korea

Tel: +82-33-248-2215

Fax: +82-33-256-3420

E-mail: shha@hallym.ac.kr

Received: October 11, 2018

Revised: November 20, 2018

Accepted: November 20, 2018

This study is supported by Hallym University Research Fund (HRF-201809-008).
Objectives: This study aimed to examine speech outcomes in Korean-speaking children with bilateral cleft lip and palate (BCLP) at 3 or 4 years of age after primary palatal surgery using the Cleft Audit Protocol for Speech - Augmented - Korean modification. Methods: This study selected 58 children born with non-syndromic BCLP who received primary palatal surgery. Blind analyses were conducted based on the children's audio-recorded speech samples to determine the presence and severity of resonance and articulation problems, and to rate whether there is a perceived need for secondary palatal repair or speech therapy. Results: Among the 58 children with BCLP, $40 \%$ showed significantly affected speech intelligibility, which indicated that less than $70 \%$ of their speech could be understood. Posterior nasal fricatives, back to velar, co-articulated glottal/pharyngeal errors, and nasal realization had more than $40 \%$ prevalence. The results also showed that $37.9 \%$ of children with BCLP exhibited moderate or more severe hypernasality and $51.7 \%$ had audible nasal emission. The listeners also judged that $62.1 \%$ of children required speech therapy and $36.2 \%$ of children needed to receive secondary palatal surgery for their persistent speech problems. Conclusion: This study evaluated speech outcomes of primary palatal surgery in Korean-speaking children with BCLP while controlling the related factors to speech outcomes, such as cleft type and surgeon. This study ultimately contributes to improving our current clinical care for children with cleft palate.

Keywords: Bilateral cleft lip and palate, Speech outcomes, Cleft Audit Protocol for Speech - Augmented-Korean modification
공명과 조음에 있어서 중요한 기제인 연인두 부위의 선천적인 결 함을 가지고 태어나는 구개열 아동은 언어치료사, 성형외과의, 교 정의 등의 협력적이고 다학제적인 서비스를 통해 정상적인 말 발달 을 이룰 수 있다. 구개열 아동의 정상적인 말 발달을 위해서는 구개 성형술 이후에 말-언어발달 현황을 살펴보고, 부가적인 중재 서비 스의 필요성을 결정하는 정기적인 말-언어 평가가 필수적이다. 구개 성형술 이후에 아동의 말 산출 능력을 객관적으로 살펴보는 평가 는 구개열 아동을 위한 중재 서비스 개선을 촉진하고 궁극적으로 구개열 아동 개인의 삶의 질을 높이는 데 기여한다.
유럽 국가에서는 1980년대 이후로 구개열 아동의 의료 서비스 수준을 개선하고자 국가적인 규모로 여러 관련 영역에 걸쳐서 평가 가 이루어졌다. 즉 구개성형술 이후 아동의 말 문제를 포함해서 안 면 미용, 치아상태, 청력, 심리적인 면을 객관적으로 평가함으로써 수술 예후를 점검하여 최적의 통일화된 의료 서비스 시스템을 이 루고자 노력하였다. 가장 최근에 시행된 이러한 지속적인 노력의 대표적인 예는 일련의 Cleft Care UK study 시리즈이다(Al-Ghatam et al., 2015; Persson et al., 2015; Sell et al., 2015; Smallridge et al., 2015; Waylen et al., 2015). 영국 전역에 거주하고 있는 일측 구 
순구개열 아동을 대상으로 한 이 연구 시리즈에서는 아동이 5 세가 되었을 때 전반적인 발달상황을 점검함으로써 2000년대 초반에 영 국 전체에서 이루어진 표준화된 구개열 관련 서비스의 효과를 살 펴보았다. 특히 말 산출 능력의 평가는 국가적으로 표준화된 구개 열 관련 서비스 평가에서 핵심적인 부분을 차지하며, 구개열 전문 언어치료사 Debbie Sell이 중심이 되어 개발한 Cleft Audit Protocol for Speech-Augmented (CAPS-A)를 이용해 말 평가를 체계적으로 실시하였다.

국내에서도 구개성형술 이후 구개열 아동의 말 발달 현황을 파 악하고, 말 평가결과를 토대로 성공적인 구개성형술과 관련된 변인 을 파악하고자 하는 노력이 계속되어 왔다(Baek et al., 2017; Ha, Jung, Moon, \& Koh, 2014; Ha, Koh, Moon, Jung, \& Oh, 2015; Park, $\mathrm{Bae}, \mathrm{Nam}, \mathrm{Kang}$, \& Sung, 2016). 이 중 Ha 등(2014)은 302명의 다양 한 유형의 구개열 아동을 대상으로 3 세경에 구개열 클리닉에서 진 행된 말 선별평가 결과를 후향적으로 분석하였다. 의료기록을 토 대로 분석한 결과, 약 $17 \%$ 의 아동이 지속적인 연인두 기제의 문제 로 2 차 구개성형술을 필요로 하였으며, $48 \%$ 의 아동이 지속적인 말 문제로 인해 언어치료를 권고받았다. 또한 구개열 유형과 말 산출 결과가 유의미한 상관관계를 보였으며, 구개열 아동보다 구순구개 열 아동이 과다비성과 조음상의 문제를 보이는 비율이 유의미하게 높았다. $\mathrm{Ha}$ 등(2015)의 연구는 대규모 자료를 바탕으로 구개성형술 이후 구개열 아동의 말 발달을 평가함으로써 한국의 구개열 관련 서비스 현황을 제시하였으며, 구개열 아동을 위한 전문적 언어치료 의 필요성을 제안하였다는 점에서 학술적, 임상적 가치가 있다. 하 지만 외래 진료의 일환으로 언어치료사 1 인에 의해 실시된 말 선별 평가 기록을 토대로 이루어졌기 때문에 아동의 말 산출 능력을 좀 더 객관적이고 상세한 방식으로 평가한 후속 연구가 필요하다.

최근에 $\mathrm{Ha}$ (2018)는 영국의 CAPS-A를 수정번안한 검사도구를 통해 구개열 전문 언어치료사들과 함께 타당도 검증을 걸쳐 "한국 판 구개열 말 평가”를 개발하였다. “한국판 구개열 말 평가”에서는 임상현장에서 수집된 다양한 아동의 말 샘플을 토대로 아동의 말 산출 능력을 (1) 조음, (2) 말명료도, (3) 공명, (4) 들리는 비누출, (5) 음성 영역별로 평가하도록 하였다. 구개열 아동이 가장 보편적으로 보이는 말 문제인 조음은 발달적, 보상적, 필연적 오류로 분류하고 각 오류 유형별로 세분화된 항목을 제시하였다. 특히 보상적 오류 는 중설구개음화와 같이 앞쪽 구강 기제를 사용하지만 조음위치나 방법 면에서 오류를 보이는 패턴, 연구음화와 같이 구강 뒤쪽으로 후방화된 패턴, 성문음화나 인두음화와 같이 구강 기제를 사용하 지 않는 보상조음 패턴으로 크게 분류하여 평가 대상자가 말소리를 산출할 때 습관적으로 사용하는 조음기관의 위치를 체계적으로 살
펴볼 수 있다. 또한 조음오류의 세부 항목마다 오류 유무뿐만 아니 라 오류를 보인 음소의 개수를 토대로 아동이 보이는 조음 문제의 심각도를 평가할 수 있다. 공명 및 들리는 비누출 영역에서도 세부 항목을 제시하고 각 유형별로 등간 척도를 사용해 심각도를 평가할 수 있다. 마지막에는 조음, 공명, 음성 영역의 평가 결과를 종합하여 언어치료와 2 차 구개성형술의 필요성을 판단하여 권고하게 하였다. 따라서 “한국판 구개열 말 평가”는 구개열 아동이 일반적으로 많이 보이는 말 문제에 초점을 맞추어 세부항목 및 심각도를 보다체계적 이고 객관적으로 평가할 수 있는 기반을 제공하고 있다.

본 연구는 “한국판 구개열 말 평가”를 이용하여 1차 구개성형술 이후 양측 구순구개열 아동이 3-4세가 되었을 때의 말 발달 현황을 객관적으로 평가하고자 하였다. 3-4세가 되었을 때 말 발달 현황을 살펴본 이유는 일반적으로 생후 12 개월 즈음에 이루어지는 구개성 형술 이후에도 남아있는 연인두상의 구조적인 문제를 확인해서 2 차 구개성형술을 권고하거나, 구개열 특유의 보상적 말 패턴 소거 및 지연된 말 발달의 촉진을 위한 직접적인 언어치료가 권고되는 시기이기 때문이다. 3-4세는 말 습득이 진행되는 시기이지만 구개 열로 인한 뚜렷한 말 문제 또는 지연은 조기에 확인하여 중재할수 록 보다 좋은 예후를 기대할 수 있기 때문에 구개열 아동에게는 이 시기에 대한 평가 결과가 임상적으로 중요하다. 특별히 양측 구순 구개열 아동은 구개열 유형 중 구강 및 연인두 기제의 선천적인 결 함 정도가 가장 심하기 때문에 다각적인 임상 서비스를 장기적으로 필요로 한다(David, Smith, Nugent, Richards, \& Anderson, 2011; Farzaneh, Becker, Peterson, \& Svensson, 2009; Oosterkamp et al., 2007). 따라서 본 연구는 “한국판 구개열 말 평가”를 이용한 말 평 가를 통해 양측 구순구개열 아동의 3-4세 시점의 조음, 공명, 들리 는 비누출, 음성 등 각 영역별 말 산출 능력과 언어치료 필요성 및 추가적인 구개성형술의 필요성을 판단하고자 하였다. 또한 추가적 인 의료기록 분석을 통해 추후 진행된 언어치료 및 2 차 구개성형술 등의 중재과정을 조사하여 말 평가 결과와 비교하고자 하였다.

\section{연구방법}

\section{연구대상}

본 연구는 자료수집이 이루어진 서울아산병원 임상연구심의위 원회로부터 임상연구 계획심의(IRB) 승인을 받은 후 실시되었다. 연구는 서울아산병원 구개열 클리닉에서 1차 구개성형술을 받고 2010-2015년 사이에 클리닉 소속 언어치료실에 말-언어선별평가를 위해 내원한 423 명의 구개열 중에서 선별하였으며, 이 중 양측 구순 구개열 아동(bilateral cleft lip and palate)만을 선정하였고, 다른 신 
드롬을 동반한 아동은 배제하였다. 또한 구개열 아동의 말 산출 능 력은 구개열 유형과 구개성형술 유형 및 시기, 집도의에 따라 크게 달라질 수 있으므로(Ha et al., 2014, 2015; Henningsson et al., 2008), 이러한 주요한 변인을 통제하기 위해 한 명의 성형외과의로부터 수 술을 받은 양측 구순구개열 아동만을 연구에 포함시켰다.

또한 만 3-4세 사이 말-언어선별검사를 통해 공식 조음평가 및 공명검사를 받고, 이에 대한 음성샘플이 수집된 아동들을 본 연구 의 대상자로 선정하였다. 그 결과 58 명(남 39명, 여 19명)의 아동이 본 연구에 포함되었으며, 말-언어선별평가 당시 이들의 연령은 30-48 개월 $(\mathrm{SD}=4.65)$ 이었고, 평가 음성샘플 수집 시의 평균연령은 40.89 개월이었다. 모든 아동은 구강 및 연인두 기제의 결함 정도에 따라 제3저자에 의해 (modified) two flap 혹은 three flap, two stage palatoplasty의 기법으로 1차 구개성형술을 받았다(수술 당시 평균 연 령=12.22개월, $\mathrm{SD}=1.73$ ). Two stage palatoplasty를 받은 아동은 4 명으로 12-15개월에 연구개 봉합술을 받은 후에 14-25개월에 경구 개 봉합술을 받았다.

\section{연구절차}

본 연구는 만 3-4세에 수집된 평가 음성자료와 병원진료기록을 기반으로 실시되었다. 제 2 저자가 구개성형술 이후 정기적으로 이루 어지는 구개열 클리닉에서의 말-언어선별평가를 실시하였으며 평 가 시 아동의 음성자료를 수집하였다. 음성자료에는 우리말조음음 운검사(U-TAP; Kim \& Shin, 2004)의 낱말, 1-10까지 숫자세기, 문 장 따라말하기, 자발화가 포함되었다. 문장 따라말하기 과제는 모 음환경에 따라 과다비성 정도가 달라지는 아동을 보다 정확하게 평가하기 위해서 Kim, Sim과 Choi (2001), Ha와 Shin (2017)의 연 구에서 사용된 문장을 선택하여 사용하였다. 고모음, 저모음 또는 혼합모음 환경에 구강자음으로만 구성된 문장으로, 어린 연령의 아동도 쉽게 따라 말할 수 있도록 각각 $4,8,16$ 음절로 이루어져 있 다. 그리고 구개열과 관련된 말 문제를 보다 자세히 객관적으로 살 펴보기 위해 평가자의 편향성을 통제하고자 오디오 자료만을 토대 로 암맹 분석(blind analysis)을 실시하였다. 수집된 말 음성 자료는 암맹 분석을 위해 아동 발화 외에 자료 수집 당시 포함된 보호자나 언어치료사의 발화는 모두 삭제하여 편집하였다. 이후 한국판 구개 열 말 평가(the Cleft Audit Protocol for Speech-Augmented-Korean Modification; Ha, 2018)를 사용하여 편집한 말 음성자료를 분 석하였다. “한국판 구개열 말 평가”를 이용하여 아동이 조음 오류 를 보일 경우 먼저 발달적 조음오류, 보상적 오류, 필연적 오류인지 판단하였다. 아동이 보상적 오류를 보일 경우 구체적으로 그 오류 유형이 중설구개음화, 연구개음화, 인두음화, 성문음화, 후비강 마
찰음화, 비강 마찰음화, 동시조음인지를 판단하고, 필연적 오류를 보일 경우 구강자음의 약화, 파열음의 비음화, 마찰음/파찰음의 활 음화인지 판단하여 각 오류의 출현 여부를 판단하였다. 또한 조음 영역은 3 점 척도 $(0=$ 없음, $1=1$ 개 혹은 2 개의 목표자음의 오류, $2=3$ 개 이상의 목표자음의 오류)를 이용하여 해당 오류 유형을 보 이는 자음의 수를 대략적으로 표기하였다. 두 번째 말명료도 측면 은 7점 척도 $(0=$ 정상규준, $1=$ 아동의 말 모두 이해 가능하나 또래 에 비해 떨어짐, $2=$ 아동의 말 $70 \%$ 이상 이해가능, $3=$ 아동의 말 $50 \%-70 \%$ 이해가능, $4=$ 아동의 말 $30 \%-50 \%$ 이해가능, $5=$ 아동의 말 $10 \%-30 \%$ 이해가능, $6=$ 아동의 말 모두 이해 불가능)를 이용하 여 평가하였다. 공명 영역은 과다비성과 과소비성 여부를 판단한 뒤 과다비성은 7점척도 $(0$ 점=없음, 1 점 =미비, 2점=경도, 3 점=경 중도, 4 점 $=$ 중도, 5 점 $=$ 심중도, 6 점 $=$ 심도 $)$ 로, 과소비성은 2 점 척도 $(0=$ 없음, $1=$ 존재함 $)$ 로 평가하였다. 들리는 비누출은 2 점 척도로 평가하였으며, 마지막으로 아동의 음성 문제 여부를 강도, 음도, 음 질별로 2점 척도로 평가하였다.

제 1,2 저자와 함께 구개열 전문 언어치료사 1 인, 총 3 명이 평가자 로 참여하였으며 모두 구개열 아동 말 평가와 관련된 임상 및 연구 경력이 7년 이상이었다. 평가자 3인은 “한국판 구개열 말 평가" 개 발 당시 타당도 검증에 참여해 본 연구 당시 해당 평가도구 사용에 익숙해져 있었다. 본 연구에 포함된 전체 음성자료를 분석하기에 앞서 전체 음성자료의 $12 \%$ 에 해당하는 8 명의 양측 구순구개열 아 동의 음성자료를 무작위로 뽑아 1 차적으로 독립적으로 분석하였 다. 이러한 작업을 통해 본 연구를 실시하기 전에 “한국판 구개열 말 평가”의 평가 세부항목을 다시 확인하면서 평가자 간의 분석 기 준을 최대한 통일하고자 하였다. 8 명 아동의 평가 결과는 본 연구의 평가자 내, 평가자 간 신뢰도 자료로 사용하였다. 그리고 1 차 분석 을 마치고 1-2주일 이내로 전체 음성 자료를 각 평가자가 독립적으 로 분석하였다. 평가자 3 인의 평가 결과를 토대로 아동별, "한국판 구개열 말 평가” 항목별 최종결과를 도출하였는데, 평가자 3 인 중 2 인 이상이 동일하게 평정한 값을 최종 평가결과로 산정하였다. 만 약 평가자 3 인이 모두 다른 반응을 했을 경우에는 평균값을 최종 평가결과로 정하였다. 구개열 클리닉에서 추후 진행된 언어치료, 2 차수술 등의 중재과정에 대한 확인은 의료기록 분석을 통해 이루 어졌다.

\section{신뢰도}

음성샘플 평가의 신뢰도를 위해 전체 자료의 $12 \%$ 를 임의로 선정 하여 급내 상관계수(intraclass correlation coefficient, ICC)를 이용 하여 평가자 간, 평가자 내 신뢰도를 확인하였다. 급내 상관계수는 
SPSS 22.0 프로그램을 사용하여 95\%의 신뢰구간을 설정하고 절대 동의와 이원혼합모델을 기본으로 구하였다. 신뢰도 분석은 전체 항 목을 모두 통합해서 살펴본 후에 조음, 말명료도, 과다/과소비성과 들리는 비누출을 포함하여 공명, 음성, 임상적 권고사항별로 분석 하였다. 신뢰도 분석 결과는 Table 1에 정리하였다. 평가자 간 신뢰 도는 전체 항목을 모두 통합해서 분석한 경우 ICC가 .88로 양호한 일치도를 보였고 각 하위 항목은 .58 에서 .98 까지의 ICC를 보여 중 간 정도에서부터 우수한 정도까지의 평가자 간 신뢰도를 보였다. 평 가자 내 신뢰도는 전체 항목을 모두 통합해서 분석한 경우에는 평 가자 3인이 각각 .91, .91, .93으로 모두 우수한 일치도를 보였다. 하 위 평가항목별로는 평가자 1은 .72-.99, 평가자 2는 .54-.99, 평가자 3 은 .61-.96의 ICC를 보여 평가자 3 인 모두 중간 정도에서부터 우수 한 정도까지의 평가자 내 신뢰도를 보였다.

\section{연구결과}

\section{조음}

“한국판 구개열 말 평가”의 조음 영역에서 발달적 오류는 제외하 고 구개열 아동 및 연인두 기능부전 환자들이 자주 보이는 보상조 음 오류 및 필연적 오류만을 제시하였다. 발달적 오류를 본 연구에 서 제외한 이유는 연구대상자가 말소리 습득 과정 중에 있으며 아 동에 따라 다양한 발달적 오류를 보이는 것이 일반적인 3-4세이기 때문이다.

조음 항목의 분석결과는 Tables 2와 3에 각각 제시하였다. 적어 도 두 개 이상의 자음에서 연구개음화, 후비강 마찰음화, 성문음화, 동시조음을 보이는 아동 비율은 $40-50 \%$ 로, 상대적으로 높은 출현 율을 보였다. 이 중 후비강 마찰음화를 보인 아동이 $50.0 \%$ 로 가장 높은 출현율을 보였고, 연구개음화는 $44.8 \%$, 동시조음 $43.1 \%$ 순으 로 나타났다. 그리고 성문음화를 보인 아동은 23 명으로 $39.6 \%$ 였고, 이어서 중설구개음화는 $20.7 \%$, 인두음화 $17.2 \%$, 비강마찰음화

Table 1. Intraclass correlation coefficients from intra-rater and inter-rater reliability analysis

\begin{tabular}{lcccc}
\hline & \multirow{2}{*}{$\begin{array}{c}\text { Intra- } \\
\text { Speech parameter }\end{array}$} & \multicolumn{3}{c}{ Inter-rater } \\
\cline { 3 - 5 } & rater & Listener 1 & Listener 2 & Listener 3 \\
\hline Entire parameters & .88 & .91 & .91 & .93 \\
Articulation & .58 & .72 & .81 & .88 \\
Speech intelligibility & .91 & .88 & .91 & .96 \\
Resonance & .98 & .99 & .99 & .96 \\
Voice & .73 & .74 & .59 & .61 \\
Clinical decision \& recommendation & .65 & .87 & .54 & .69 \\
\hline
\end{tabular}

$6.9 \%$ 의 아동에게서 관찰되었다.

보상조음오류는 3점 척도로 분석되었는데, 3 개 이상의 자음에서 해당 보상조음을 보인 아동 비율을 먼저 살펴보면, 성문음화는 $31 \%$, 동시조음은 $37.9 \%$ 로 두 영역 모두 $30 \%$ 이상의 아동에게서 관 찰되었다. 연구개음화와 후비강마찰음화는 각각 $20.7 \%, 24.1 \%$, 중 설구개음화를 보인 아동은 $5.2 \%$ 이었으며, 인두음화는 $3.4 \%$ 의 아동 에게서 보였고, 비강마찰음화를 보인 아동은 관찰되지 않았다. 즉, 양측 구순구개열 아동들이 가장 빈번하게 사용하는 보상조음의 유 형은 성문음과 인두음의 동시조음, 성문음화, 후비강마찰음화, 연 구개음화, 중설구개음화, 인두음화, 비강마찰음화 순으로 나타났 다. 또한 한 개 혹은 두 개의 조음에서만 간헐적으로 보상조음이 나 타난 오류유형에 대한 아동의 비율은, 후비강마찰음화는 $25.9 \%$, 연 구개음화는 $24.1 \%$ 로 가장 많았으며, 중설구개음화 $15.5 \%$, 인두음 화 $13.8 \%$, 성문음화 $8.6 \%$, 동시조음화 $5.2 \%$ 순이었다.

전체 보상조음 유형에서 높은 비율로 발생한 성문음화와 성문 음/인두음의 동시조음의 경우, 오류를 보인 대부분의 아동이 3 개 이상의 자음에서 오류를 보여 해당 보상조음을 보일 경우에는 여 러 자음에 걸쳐 오류가 빈번하게 발생하였다. 반면 연구개음화와 후비강마찰음화는 높은 비율의 오류를 보였지만, 한두 개의 자음 에서 오류를 보이는 아동과 3 개 이상의 자음에서 오류를 보이는 아

Table 2. The presence of compensatory articulation errors

\begin{tabular}{lccc}
\hline Compensatory articulation errors & $\begin{array}{c}\text { Two conso- } \\
\text { nants } \\
\text { affected }^{\text {a }}\end{array}$ & $\begin{array}{c}\text { Three or more } \\
\text { consonants } \\
\text { affected }^{\text {a }}\end{array}$ & Total \\
\hline Mid-dorsum palatal stop & $9(15.5)$ & $3(5.2)$ & $12(20.7)$ \\
Back to velar & $14(24.1)$ & $12(20.7)$ & $26(44.8)$ \\
Pharyngeal & $8(13.8)$ & $2(3.4)$ & $10(17.2)$ \\
Glottal & $5(8.6)$ & $18(31.0)$ & $23(39.6)$ \\
Posterior nasal fricative & $15(25.9)$ & $14(24.1)$ & $29(50.0)$ \\
Active nasal fricative & $4(6.9)$ & $0(0)$ & $4(6.9)$ \\
Co-articulated glottal/pharyngeal & $3(5.2)$ & $22(37.9)$ & $25(43.1)$ \\
\hline
\end{tabular}

Values are presented as number (\%).

andicates the number of children who showed two/three or more consonants affected.

Table 3. The presence of obligatory articulation errors

\begin{tabular}{lccc}
\hline $\begin{array}{l}\text { Obligatory articulation } \\
\text { errors }\end{array}$ & $\begin{array}{c}\text { Two consonants } \\
\text { affected }^{\text {a }}\end{array}$ & $\begin{array}{c}\text { Three or more } \\
\text { consonants affected }^{\text {a }}\end{array}$ & Total \\
\hline Weak consonants & $6(10.3)$ & $16(27.6)$ & $22(37.9)$ \\
Nasal realization & $15(25.9)$ & $8(13.8)$ & $23(39.7)$ \\
Gliding & $2(3.4)$ & $0(0)$ & $2(3.4)$ \\
\hline
\end{tabular}

Values are presented as number (\%).

alndicates the number of children who showed two/three or more consonants affected. 
동의 비율이 유사하였다. 또한 전체 오류 비율에서 상대적으로 낮 은 비율을 보였던 중설구개음화와 인두음화, 비강마찰음화는 주로 1-2개의 자음에서만 오류가 관찰되었다.

필연적 오류 측면을 살펴보면(Table 3), 파열음의 비음화 양상은 $39.7 \%$, 구강자음의 약화는 $37.9 \%$, 활음화 양상은 $3.4 \%$ 의 비율로 나 타났다. 구강자음의 약화는 한두 개의 자음에서 간헐적으로 오류 가 발생하는 아동의 비율이 $10.3 \%$ 인 반면 3개 이상의 자음에서 오 류를 보인 아동이 $27.6 \%$ 로 나타났다. 파열음의 비음화 양상은 한 두 개의 자음에서 오류가 발생하는 아동의 비율이 $25.9 \%$ 이고, 3 개 이상의 자음에서 오류를 보인 아동은 $13.8 \%$ 로 나타났다. 유음화 양상은 $3.4 \%$ 에서 관찰되었는데, 두 명 모두 한 개 혹은 두 개의 자 음에서 오류가 발생되었다.

\section{말명료도}

1 차 구개성형술을 받은 후 만 3-4세에 실시된 "한국판 구개열 말 평가”에서 나타난 말명료도 분포비율은 Table 4 와 같다. BCLP 전 체 58 명 대상자 중 $34.5 \%$ 의 아동의 말명료도가 정상범주에 포함되 었고, 발화의 $70 \%$ 이상을 알아들을 수 있는 수준의 명료도를 유지 하고 있는 아동은 $24.1 \%$ 로 나타났다. $70 \%$ 미만의 말명료도를 나타 내어 명료도에 여전히 부정적 영향을 받고 있는 것으로 나타나는 아동은 $41.4 \%$ 로 나타났으며, 이들 중 말을 전혀 알아들을 수 없는 수준의 발화 명료도를 보인 아동도 1 명이 관찰되었다.

\section{공명과 비누출}

7점 척도를 이용하여 평가한 과다비성의 심각도별 분포를 전체 적으로 살펴보면, 미비함(minimal) $5.2 \%$, 경도(mild) $22.4 \%$, 경중 도(mild to moderate) $34.5 \%$, 중도(moderate) $20.7 \%$, 심중도(moderate to severe) $15.5 \%$, 심도(severe) $1.7 \%$ 로 나타났다. 과소비성은 평가 당시 58 명 중 아무도 보이지 않는 것으로 나타났다. 또한 들리 는 비누출(audible nasal emission)은 $51.7 \%$ 에서 나타났다. 해당 결 과는 Table 5에 제시하였다.

Table 4. The prevalence of outcomes of speech intelligibility

\begin{tabular}{lc}
\hline Speech intelligibility & $\mathrm{N}(\%)$ \\
\hline Within normal range & $20(34.5)$ \\
Above $70 \%$ intelligible & $14(24.1)$ \\
$50 \%-70 \%$ & $13(22.4)$ \\
$30 \%-50 \%$ & $8(13.8)$ \\
$10 \%-30 \%$ & $2(3.5)$ \\
Impossible to understand & $1(1.7)$ \\
\hline
\end{tabular}

\section{음성}

음성 측면에서는 강도, 음도, 음질에 대해서 정상범위에 포함이 되는지 2점 척도 $(0=$ 정상, $1=$ 문제있음 $)$ 로 측정하였는데, 그 결과 음도에서 문제를 보이는 아동은 관찰되지 않았으며, 강도 측면에서 는 $3.4 \%$, 음질 측면에서는 $24.1 \%$ 의 아동이 문제가 있는 것으로 평 가되었다.

\section{임상적 권고사항: 2차수술 여부와 언어치료 필요성}

임상적 권고사항 항목에서는 공명, 조음, 음성 측면에서 아동의 주요한 문제를 종합적으로 고려하여 평가 아동이 2 차 구개성형술 과 언어치료가 필요한지 판단하였다. 연구 결과, 58 명의 대상자 중 약 $62.1 \%$ 의 아동이 언어치료가 필요하고, $25.9 \%$ 는 언어치료가 필 요하지 않은 것으로 판단되었으며, 나머지 $12.1 \%$ 는 판단이 보류되 었다. 또한 2 차 수술 필요성 여부에 대해서는 $36.2 \%$ 의 아동이 수술 이 필요하고, $31.0 \%$ 는 수술이 필요하지 않은 것으로, 그리고 나머 지 $32.8 \%$ 는 수술에 대한 결정이 보류되었다.

본 연구의 대상자인 BCLP 58명이 서울아산병원 구개열 클리닉 에서 진행된 중재과정에 대한 의료기록 분석을 추가로 실시하여 “한국판 구개열 말 평가”를 이용한 본 연구결과와 실제 임상 판단 및 결과와 비교하였다(Figure 1). 의료기록 분석 실시 결과, 2 차 수 술을 받은 대상자 수 비율은 $36.2 \%$ 이고, 수술을 받지 않은 아동은 $56.9 \%$, 수술 여부 판단에 대해 유보 중인 아동이 6.9\%로 나타났다. 실제 2 차 수술을 받은 양측 구순구개열 아동의 비율은 본 연구의 암맹 분석 결과와 동일하게 나왔다. 추가로 본 연구의 평가결과와 의료기록에서의 임상적 권고가 아동별로 실제로 일치했는지 살펴 본 결과, 2 차 수술을 실제 받은 21 명 중 14 명이 수술이 필요하다고 평가되어 $66.6 \%$ 의 민감도를 보였다. 또한 2 차 수술을 받지 않은 33 명 중 14 명이 필요없다고 평가되거나 13 명이 수술에 대한 판단이

Table 5. The prevalence of outcomes of hypernasality and presence of audible nasal emission

\begin{tabular}{lc}
\hline & $\mathrm{N}(\%)$ \\
\hline Hypernasality & $3(5.2)$ \\
Minimal & $13(22.4)$ \\
Mild & $20(34.5)$ \\
Mild to moderate & $12(20.7)$ \\
Moderate & $9(15.5)$ \\
Moderate to severe & $1(1.7)$ \\
Severe & \\
Audible nasal emission & $30(51.7)$ \\
Presence of audible nasal emission & \\
\hline
\end{tabular}

Values are presented as number (\%). 

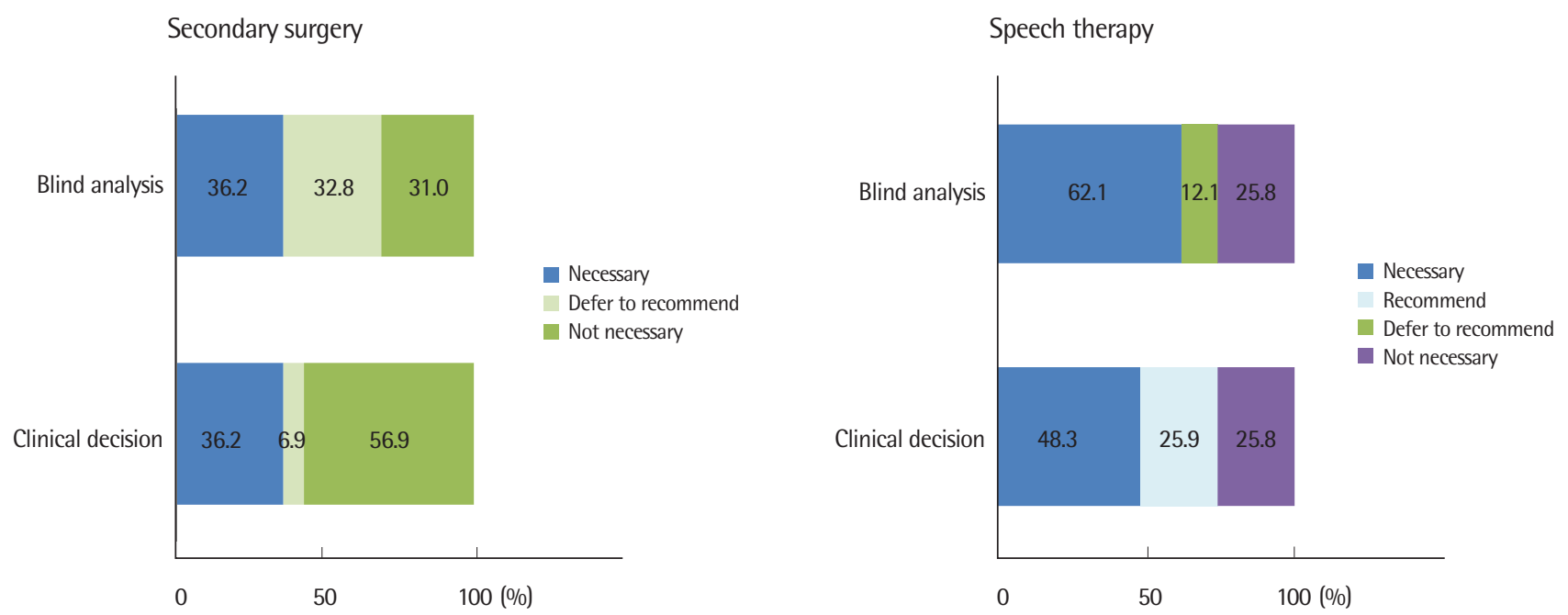

Figure 1. Comparison blind analysis results and clinical decisions of secondary palatal repair and speech therapy.

보류되어졌다.

또한 언어치료 실시 여부에 대해서는 $48.3 \%$ 의 아동이 언어치료 를 권고받은 후 언어치료를 시작하였고, $25.9 \%$ 의 아동은 언어치료 를 권고받았으나 아직 언어치료 시작 전이었으며, $25.8 \%$ 의 아동들 은 언어치료가 필요하지 않은 것으로 판단되어졌다. 언어치료와 관 련된 암맹 분석 결과와 의료 기록에서의 임상적 권고가 아동별로 실제로 일치했는지 분석한 결과, 실제 임상에서 43 명이 언어치료를 받거나 권고를 받았는데 이 중 30 명이 언어치료가 필요한 말 문제 를 가지고 있다는 결과가 나와 $69.8 \%$ 의 민감도가 나타났다. 실제 임상에서 언어치료를 권고받지 않은 15 명 중 6 명이 언어치료가 필 요없다는 평가결과를 받았으며, 3 명은 언어치료 필요성에 대한 판 단이 보류되었다.

\section{논의 및 결론}

본 연구는 “한국판 구개열 말 평가”를 이용하여 구개열 전문 언 어치료사 및 연구자 3 인의 암맹 분석을 통해 한 명의 동일한 성형외 과의로부터 구개성형술을 받은 3-4세 양측 구순구개열 아동의 말 발달 현황을 객관적으로 평가하고자 하였다. 이러한 연구를 통해 구개열 아동의 말 산출결과에 주요하게 영향을 끼치는 변인인 구개 열 유형과 수술 집도의의 경험과 수술 유형을 통제하면서 아동의 음성만을 토대로 아동의 말 문제 여부를 객관적으로 평가하고자 하였다.

먼저 “한국판 구개열 말 평가”의 하위 평가 영역 중 조음은 보상 적 오류와 필연적 오류로 나누어서 평가하였다. 보상조음 측면에서
는 후비강마찰음화, 연구개음화, 성문음과 인두음의 동시조음, 성 문음화 순서로 높은 출현율을 보이면서 많은 수의 양측 구순구개 열 아동들이 보상적 오류패턴을 3-4세에 보이는 것으로 나타났다. 또한 구강자음의 약화와 파열음의 비음화와 같은 필연적 오류를 보 이는 아동도 전체 대상자 중 각각 $38 \%, 40 \%$ 를 차지하였다. 일반적 으로 보상적 오류는 구개열 아동이 말 습득과정에서 발달시킨 잘 못된 말 습관 또는 패턴과 관련이 있어서 언어치료를 통해서 소거 해야 한다. 따라서 본 연구결과는 대다수의 3-4세 양측 구순구개열 아동이 보상 조음을 소거하는 언어치료를 필요로 함을 제안하고 있다. 또한 필연적 오류는 보상적 오류와는 달리 연인두 기관의 남 아있는 구조적 문제와 관련된 조음오류 유형으로 구조적 문제를 해결하는 수술적 중재가 필요함을 나타내는 패턴이다. 따라서 2 차 구개성형술의 필요성을 시사하는 필연적 오류의 출현율과 공명 영 역의 과다비성에서의 결과를 종합하면 30-40\%의 양측 구순구개 열 아동들이 추가적인 수술이 필요하다고 판단할 수 있다.

말명료도 평가결과는 전체 58명 중 24명(40\%)은 전체 발화에서 $70 \%$ 미만으로 이해가능한, 손상된 말명료도를 보였다. 3 세 일반아 동의 경우 일반적으로 $75 \%$ 정도의 말명료도를 보인다는 점을 고려 한다면(Coplan \& Gleason, 1988; Kim \& Ha, 2012) 약 40\%의 양측 구순구개열 아동은 또래와 비교해 낮은 말명료도를 보인다고 할 수있다.

공명 영역 중 과다비성 측면에서는 사회적으로 용인되는 말(acceptable speech)로 간주되는 수준인 경도(mild) 이하의 과다비성 (Hardin-Jones \& Jones, 2005; Ha et al., 2014)을 보인 아동은 27.6\% 로 나타났다. 수술적 중재를 고려해야 할 정도의 과다비성 심각도 
를 보이는 중등도(moderate) 혹은 그 이상의 과다비성을 보인 아동 은 37.9\%로 나타났다. 또한 들리는 비누출(audible nasal emission) 은 $51.7 \%$ 의 아동에게서 나타났다. 들리는 비누출은 연인두 기능부 전에 의해서도 발생하지만 구개누공(fistula)으로도 발생하는데 본 연구에서 평가된 양측 구순구개열 아동은 모두 8-10세경에 치조부 위 골이식술을 받을 예정으로 치조 부위에 구강에서 비강으로 연 결되는 구개누공이 있다. 따라서 치조부위의 구개누공으로 인해 중등도 이상의 과다비성 문제보다 들리는 비누출을 보이는 아동의 수가 더 많게 나타난 것으로 추측해 볼 수 있다. 음성측면에서는 아 동 중 $24.1 \%$ 가 거친 음성과 같은 음질상의 문제를 보이는 것으로 나타났는데 성문음화와 같은 보상 조음으로 인해 이차적으로 음 질상의 문제를 보이는 양측 구순구개열 아동도 상당수 있는 것으 로 나타났다.

마지막으로 공명, 조음, 음성 측면에서 아동의 주요한 문제를 종 합적으로 고려하여 임상적 판단 및 권고사항을 내리는 항목에 대 한 결과는 58 명의 대상자 중 약 36 명(62.1\%)의 아동이 언어치료가 필요한 것으로 나타났다. 반면에 15 명(25.9\%)은 언어치료가 필요하 지 않은 것으로 판단되었으며, 나머지 7명(12.1\%)은 발달적 오류만 을 보이거나, 조음오류 심각도가 상대적으로 낮아 판단이 보류되었 다. 또한 21 명(35\%)의 아동이 지속적으로 남아있는 구조적인 문제 로 인해 심한 말 문제를 보여 2차 구개성형술이 필요한 것으로 평가 되었다. 이러한 연구결과는 해당 구개열 클리닉에서 말선별 평가 당 시 내렸던 임상적 판단 및 의료기록 분석결과와 거의 비슷하였다. 의료기록 분석 결과, $74.2 \%$ 의 아동이 언어치료를 권고받아 언어치 료를 시작하였으며, $25.9 \%$ 의 아동은 3-4세 당시 정상적으로 말 습 득을 해 나가는 것으로 확인되어 언어치료가 필요하지 않다고 권고 하였다. 마찬가지로 의료 분석 결과 2 차 수술을 받은 대상자 수 비 율은 36.2\%로 “한국판 구개열 말 평가”로 구개열 전문 언어치료사 및 연구자가 내린 암맹 분석결과와 동일한 수치가 나왔다. 하지만 두 분석결과가 아동 개인별에서도 얼마나 일치했는지 추가적으로 분석을 실시한 결과 대체로 약 $66 \%-67 \%$ 의 민감도만을 보이는 것 으로 나타났다. 2 차 수술과 언어치료의 필요성과 관련하여 “한국 판 구개열 말 평가”를 토대로 아동의 음성샘플만을 듣고 평가한 결 과가 실제 임상에서 진행된 사항과 일치도가 다소 낮은 이유는 평 가 대상 일부 아동이 정확한 판단이 보류된 것과 관련이 있다. 많은 수의 구순구개열 아동은 초기 발성 단계에서부터 발달이 지연되어 느린 말-언어발달을 보인다. 임상적 판단을 위한 말-언어평가를 실 시하는 3-4세경에 일부 아동들이 서서히 말-언어발달을 보이면서 일반 발달을 따라가는 경우도 있지만 여전히 많은 수의 아동들이 평가 상황에서 제한된 수행력을 보여 임상적 판단이 보류되어지기
도 한다. 또한 실제 임상에서의 2 차 수술과 언어치료의 여부는 아 동의 말 문제 외에도 부모의 양육 태도, 2 차 수술에 대한 부모의 걱 정과 거부감, 아동의 전반적인 발달 현황 등 다양한 변인에 의해서 결정되어지기 때문에 말 평가 결과와 상이하게 이루어질 수 있다. 추후 연구에서는 양측 구순구개열 아동의 2 차 수술과 언어치료와 관련된 변인을 종합적으로 자세하게 살펴보는 것이 필요하겠다.

본 연구에서 살펴본 양측 구순구개열 아동은 선천적인 결함 정 도가 구개열 유형 중에서 가장 심각해 다른 유형에 비해 안면 성장, 치아 및 교합 상태, 청력과 말 산출 면에서 예후가 좋지 않아 여러 전문가의 다각적인 중재 서비스가 장기적으로 필요하다(David et al., 2011; Farzaneh et al., 2009; Oosterkamp et al., 2007). 302명의 한국 구개열 아동을 대상으로 3 세경에 구개열 클리닉에서 진행된 말 선별평가 결과를 후향적으로 분석한 $\mathrm{Ha}$ 등(2014)의 연구에서는 구개열 유형을 일측 구순구개열, 양측 구순구개열, 구개열, 점막하 구개열로 네 집단으로 나누어 말 산출 능력을 살펴보았다. $\mathrm{Ha}$ 등 (2014)의 연구에서는 38명의 양측 구순구개열 아동 중에서 $50 \%$ 의 아동이 보상조음을 보이고, $34 \%$ 의 아동이 중등도 이상의 뚜렷한 과다비성을 보이는 것으로 나타나 네 집단 중 보상조음과 공명 문 제를 보이는 비율이 가장 높았다. 또한 언어치료와 2 차 성형술을 필 요로 하는 비율이 각각 $63.2 \%$ 와 $31.6 \%$ 로 나타나 구개열 유형 중에 서 높게 나타났다. 본 연구에서 실시된 암맹 분석 및 의료기록 분석 결과와 $\mathrm{Ha}$ 등(2014)의 후향적 분석 결과에서 모두 양측 구순구개 열 아동의 언어치료와 2 차 구개성형술을 필요로 하는 비율은 비슷 한 수치로 나타났다. 세 분석 결과를 종합하면 60-72\%의 양측 구 순구개열 아동이 조음 문제로 3-4세경에 언어치료를 권고받고 있 으며, $30-35 \%$ 의 아동이 지속적인 연인두 구조 및 기능문제로 인한 공명 문제로 2 차 구개성형술을 권고받는다.

본 연구는 구개열 유형 및 수술과 관련된 중요 변인을 통제하고 비교적 많은 수의 양측 구순구개열 아동의 자료를 살펴보았다. 또 한 구개열과 관련된 말 문제를 체계적으로 살펴볼 수 있는 검사도 구와 아동의 음성자료만을 토대로 구개열 전문 언어치료사와 연구 자가 객관적으로 말 문제 양상을 평가해 3-4세 양측 구순구개열 아 동의 말 발달 현황을 제시했다는 점에서 의미가 있다. 3-4세 연령대 는 말 습득이 진행되는 과정이지만, 말 발달에 대한 아동 간 개인차 가 줄고 아동의 협조와 주의집중 시간이 증가해 아동의 말 산출을 직접적으로 평가할 수 있는 시기이다. 따라서 2 차 수술과 언어치료 등의 추후 필요한 부가적인 서비스에 대한 임상적 판단이 비교적 명확해진다. 언어치료사에 의한 직접적인 중재도 가능하기 때문에 이 시기에 말-언어발달 문제를 확인해서 적극적으로 중재를 제공한 다면 이 후 말-언어문제로 인해 아동이 보일 수 있는 정서적, 사회적, 
학습적인 면에서 2 차적인 문제가 발생하는 것을 예방할 수 있다. 또 한 언어치료를 통해서 잘못된 말 패턴과 습관을 소거하는 데 상대 적으로 시간이 적게 걸리고 좋은 예후를 얻을 수 있기 때문에 이 시 기에 아동의 말 산출 능력을 객관적으로 살펴보는 것은 중요하다.

한국의 대표적인 구개열 클리닉에서 한 명의 동일한 성형의로부 터 수술을 받은 아동들을 대상으로 진행했다는 점이 본 연구의 큰 강점과 의의라고 할 수 있다. 하지만 이 점이 본 연구결과를 전체 (구순)구개열 아동의 말 발달 현황으로 일반화하는 데 제한점도 될 수 있으므로 본 연구결과를 한국의 구순구개열 아동의 전체 말 발 달 결과로 해석하는 것에는 주의를 기울여야 한다. 또한 추후연구 에서 구개열 말 문제를 보다 정확하고 타당하게 분석하기 위해서는 조음과 공명 문제 면에서 다양한 수준이 포함될 수 있도록 구순구 개열 아동만이 아닌 일반아동의 음성자료까지 포함해 암맹 분석 을 실시하는 것이 필요하다.

본 연구에서 살펴본 3-4세는 말 발달과정 중에 있는 연령대이고 일부 구개열 아동은 발달 초기에는 말 발달 지연을 보이다가 이후 점진적으로 발달이 향상되어 말소리 산출이 정상범위에 이를 수도 있기 때문에 3-4세의 말 발달 수준만으로 임상적 중재의 효과를 판 단하는 것은 제한적일 수 있다. 따라서 추후 동일 아동을 장기적으 로 관찰하여 말 습득이 완성되고, 초등학교에 입학하는 5-6세 시점 에 아동이 최종적으로 어떠한 말 산출 능력을 갖추었는지 살펴보 는 것이 필요하다. 그리고 본 연구에서는 말소리 습득과정 중인 아 동의 연령 특성상 발달적 오류에 대한 분석은 제외하였으나 추후 연구에서는 구개열 아동에게서 관찰되는 발달적 오류의 특성에 대 해서도 분석이 함께 이루어져야 할 것이다.

\section{REFERENCES}

Al-Ghatam, R., Jones, T. E. M., Ireland, A. J., Atack, N. E., Chawla, O., Deacon, S., ... \& Waylen, A. (2015). Structural outcomes in the Cleft Care UK study. Part 2: dento-facial outcomes. Orthodontics \& Craniofacial Research, $18,14-24$

Baek, R. M., Kim, B. K., Jeong, J. H., Ahn, T., Park, M., \& Han, J. (2017). The effect of age at surgery and compensatory articulation on speech outcome in submucous cleft palate patients treated with double-opposing Z-plasty: a 10-year experience. Journal of Plastic, Reconstructive \& Aesthetic Surgery, $70,646-652$.

Coplan, J., \& Gleason, J. R. (1988). Unclear speech: recognition and significance of unintelligible speech in preschool children. Pediatrics, 82, 447-452. David, D. J., Smith, I., Nugent, M., Richards, C., \& Anderson, P. J. (2011). From birth to maturity: a group of patients who have completed their protocol management. Part III. Bilateral cleft lip-cleft palate. Plastic and Reconstructive Surgery, 128, 475-484.

Farzaneh, F., Becker, M., Peterson, A. M., \& Svensson, H. (2009). Speech results in adult Swedish patients born with bilateral complete cleft lip and palate. Scandinavian Journal of Plastic and Reconstructive Surgery and Hand Surgery, 43, 207-213.

Kim, M., \& Ha, S. (2012). Speech intelligibility development of children aged 24 to 48 months according to listener's familiarity with child's speech. Communication Sciences \& Disorders, 17, 582-590.

Ha, S. (2018). The cleft audit protocol for speech-augmented-Korean modification: reliability test. Communication Sciences \& Disorders, 23, 1-10.

Ha, S., Koh, K. S., Moon, H., Jung, S., \& Oh, T. S. (2015). Clinical outcomes of primary palatal surgery in children with nonsyndromic cleft palate with and without lip. BioMed Research International, 2015, 185459.

Ha, S., Jung, S., Moon, H., \& Koh, K. (2014). Speech outcomes of children with cleft palate following primary palatal surgery: a retrospective study. Communication Sciences \& Disorders, 19, 391-401.

Ha, S., \& Shin, I. (2017). Effects of vowel context and stimulus length on testretest nasalance variability between children and adults with normal speech. Communication Sciences \& Disorders, 22, 578-586.

Hardin-Jones, M. A., \& Jones, D. L. (2005). Speech production of preschoolers with cleft palate. Cleft Palate-Craniofacial Journal, 42, 7-13.

Henningsson, G., Kuehn, D. P., Sell, D., Sweeney, T., Trost-Cardamone, J. E., \& Whitehill, T. L. (2008). Universal parameters for reporting speech outcomes in individuals with cleft palate. The Cleft Palate-Craniofacial Journal, 45, 1-17.

Kim, M., Sim, H. S., \& Choi, H. S. (2001). The effects of phonetic context and stimulus length on the nasalance score in normal adults. Korean Journal of Communication \& Disorders, 5, 1-15.

Kim, Y. T., \& Shin, M. J. (2004). Urimal Test of Articulation and Phonology (U-TAP). Seoul: Hakjisa.

Oosterkamp, B. C. M., Dijkstra, P. U., Remmelink, H. J., Van Oort, R. P., Goorhuis-Brouwer, S. M., Sandham, A., \& de Bont, L. G. M. (2007). Satisfaction with treatment outcome in bilateral cleft lip and palate patients. International Journal of Oral and Maxillofacial Surgery, 36, 890-895.

Park, T. S., Bae, Y. C., Nam, S. B., Kang, K. D., \& Sung, J. Y. (2016). Postoperative speech outcomes and complications in submucous cleft palate patients. Archives of Plastic Surgery, 43, 254-257.

Persson, M., Sandy, J. R., Waylen, A., Wills, A. K., Al-Ghatam, R., Ireland, A. 
J., ... \& Preston, R. (2015). A cross-sectional survey of 5-year-old children with non-syndromic unilateral cleft lip and palate: the Cleft Care UK Study. Part 1: background and methodology. Orthodontics \& Craniofacial Research, 18, 1-13.

Sell, D., Mildinhall, S., Albery, L., Wills, A. K., Sandy, J. R., \& Ness, A. R. (2015).

The Cleft Care UK study. Part 4: perceptual speech outcomes. Orthodontics \& Craniofacial Research, 18, 36-46.

Smallridge, J., Hall, A. J., Chorbachi, R., Parfect, V., Persson, M., Ireland, A. J.,
... \& Sandy, J. R. (2015). Functional outcomes in the Cleft Care UK study. Part 3: oral health and audiology. Orthodontics \& Craniofacial Research, $18,25-35$.

Waylen, A., Ness, A. R., Wills, A. K., Persson, M., Rumsey, N., \& Sandy, J. R. (2015). Cleft Care UK study. Part 5: child psychosocial outcomes and satisfaction with cleft services. Orthodontics \& Craniofacial Research, 18, 4755. 


\section{국문초록}

\section{구개성형술 이후 양측 구순구개열 아동의 말 산출 능력}

하승희'(교수, 제1저자, 교신저자) · 정승은(학생) · 고경석3(교수) · 오태석3(교수)

'한림대학교 언어청각학부, 한림청각언어연구소, ${ }^{2}$ 한림대학교 일반대학원 언어병리학과, ${ }^{3}$ 서울아산병원 성형외과

배경 및 목적: 본 연구는 “한국판 구개열 말 평가”를 이용해 1 차 구개성형술을 받은 양측 (구순)구개열 아동의 3-4세 시점의 말 산출을 평가하고자 하였다. 방법: 본 연구의 대상자로 1 차 구개성형술을 받은 58 명의 양측 구순구개열 아동이 최종적으로 채택되었으며, 구개 열 클리닉에서 실시된 말선별검사에서 녹음된 오디오 말자료를 기반으로 구개열 전문 언어치료사 및 연구자 3 인이 암맹 분석을 실시하 였다. “한국판 구개열 말 평가”의 하위 평가 영역별로 조음, 말명료도, 공명, 음성의 문제유무와 심각도를 판별하고, 2 차수술 여부와 언 어치료 필요성을 판단하였다. 결과: $3-4$ 세 양측 구순구개열의 말 산출 능력을 분석한 결과, 조음 영역에서는 후비강마찰음화, 연구개음 화, 성문음과 인두음으로의 동시조음와, 파열음의 비음화가 58 명의 대상아동 중 각각 24 명 이상의 아동에게서 관찰되어 $40 \%$ 이상의 출현율을 보였다. 또한 $41.3 \%$ 의 아동이 전체 발화 중 $70 \%$ 이하의 말을 이해할 수 있는 손상된 말명료도를 보이는 것으로 나타났다. 공 명 영역에서는 중등도 이상의 과다비성을 보인 아동은 $37.9 \%$, 들리는 비누출을 보인 아동은 $51.7 \%$ 로 나타났다. 평가자들은 $62.1 \%$ 의 양 측 구순구개열 아동이 언어치료가 필요하다고 판단하였으며, 2 차 수술이 추가적으로 필요한 아동은 $36.2 \%$ 로 평가하였다. 논의 및 결 론: 본 연구는 구개열 유형과 수술 집도의 등 말 산출과 관련된 요소들을 통제하여 1 차 구개성형술을 받은 아동의 말 산출 결과를 살펴 보았다. 본 연구는 양측 구순구개열 아동의 말 산출 능력을 토대로 구개열 아동을 위한 임상적 중재의 현황을 파악하고, 궁극적으로 구 개열 아동을 위한 언어평가 및 치료 증진에 기여할 것이다.

핵심어: 양측 구순구개열, 말 산출, 한국판 구개열 말 평가

본 연구는 한림대학교 교비 학술연구과제(HRF-201809-008)의 지원을 받아수행되었음.

\section{참고문헌}

김미진, 하승희(2012). 청자의 친숙도에 따라 낱말수준에서 살펴본 24-48개월 아동의 말 명료도 발달 연구. 언어청각장애연구, 17, 582-590.

김민정, 심현섭, 최홍식(2001). 음운환경과 검사어 길이가 정상성인의 비음치에 미치는 영향. 언어청각장애연구, 5, 1-15.

김영태, 신문자(2004). 우리말 조음음운 평가(U-TAP). 서울: 학지사

하승희(2018). 한국판 구개열 말 평가 개발 및 신뢰도 검사. Communication Sciences \& Disorders, 23, 1-10.

하승희, 신일산(2017). 검사어 모음환경과 길이에 따른 성인과 아동의 비음치 변이성. Communication Sciences \& Disorders, 22, 578-586.

하승희, 정승은, 문희원, 고경석(2014). 1차 구개성형술 이후 구개열 아동의 말 산출 능력: 후향적 연구. Communication Sciences \& Disorders, 19, 391-401. 